\title{
Creation and Initial Validation of the Motivation Beliefs Inventory: Measuring Leaders' Beliefs about Employee Motivation Using Four Motivation Theories
}

\author{
David C. Facer Jr. ${ }^{1}$, Fred Galloway ${ }^{1}$, Noriyuki Inoue ${ }^{1} \&$ Drea $_{\text {Zigarmi }}{ }^{2}$ \\ ${ }^{1}$ School of Leadership and Education Sciences, University of San Diego, San Diego, California, USA \\ 2 The Ken Blanchard Companies, Escondido, California, USA \\ Correspondence: David C. Facer Jr., School of Leadership and Education Sciences, University of San Diego, San \\ Diego, California, USA. E-mail: davidf-13@sandiego.edu
}

Received: January 1, 2014

Accepted: January 14, 2014

Online Published: January 20, 2014

doi:10.5430/jbar.v3n1p1

URL: http://dx.doi.org/10.5430/jbar.v3n1p1

\begin{abstract}
This article describes the development and validation of the Motivation Beliefs Inventory (MBI), a new instrument for measuring leaders' motivation beliefs. For decades, organizational scholars and a small number of motivation researchers have urged leaders to examine their beliefs related to employee motivation. Answering this challenge was difficult, however, given the lack of instruments designed to measure motivation beliefs at all, much less beliefs from a range of prevalent theories.

Using principal components and parallel analyses, the 20-item Motivation Beliefs Inventory (MBI) was created to measure motivation beliefs along four theoretical lines: reinforcement theory; expectancy-valence theory; achievement motivation theory; and self-determination theory. The instrument was validated in two studies involving large samples of businesspeople $(\mathrm{n}=1322$ and 712$)$. Validity and reliability analyses revealed the instrument demonstrates acceptable psychometric properties. Four subscales, each representing a single theory, were confirmed and demonstrated alpha coefficients as follows: reinforcement theory, .77; expectancy-valence theory, .71; achievement motivation theory, .82; self-determination theory, .77. The entire Motivation Beliefs Inventory produced a strong alpha coefficient of 77 .

The creation of a new instrument like the MBI opens fresh possibilities for both practitioners and scholars. While workplace practitioners now have the ability to measure a leader's beliefs about motivation, researchers can use the instrument to test for differences in these beliefs among leaders in different occupations, companies, industries, and countries. Given the link between leader beliefs and behavior, the article concludes with a discussion about belief strength, and the challenges and opportunities of empirically investigating leaders' beliefs about what motivates employees.
\end{abstract}

Keywords: Scale, Beliefs, Work motivation, Employee motivation, Self-determination theory, Achievement motivation, Expectancy theory, Reinforcement theory

\section{Introduction}

Motivation researchers have extensively explored what intrapersonal and social conditions catalyze, alter, and sustain human action in various contexts, including work, since the early years of the industrial revolution. Most of that research has measured the motivational experience of study participants related to a particular stimulus, task, goal, or situation. But, measuring a study participant's motivational response to an intervention does not address what that manager believes motivates someone else in the work setting. This distinction between measuring individual motivation and measuring motivation beliefs is important given that all workplace decisions and actions are predicated on beliefs. As such, a manager's workplace actions and beliefs are inseparable (Lewin, 2008). Furthermore, measuring a study participant's (e.g. a leader's) motivational experience may not offer significant predictive power about the actions a leader may take to stimulate employees' behavior. Given this historical focus, there is scant empirical research into what managers believe motivates employees. Moreover, an instrument has not been developed to measure motivation beliefs and facilitate motivation belief research. 


\subsection{Importance of the Problem}

The limited prior research on motivation beliefs has shown that leaders hold inaccurate beliefs about what motivates employees (Kovach, 1987). Such inaccuracies are important for the firm as they inform the economic offers managers extended to employees (Heath, 1999). As a routine managerial responsibility, offers associated with compensation, and reward and recognition have been shown to be based on intuitive and often erroneous combinations of beliefs (Nisbett \& Ross, 1980) - or lay theories - about what motivates others. For example, lay theories of motivation held by managers were shown to include an extrinsic incentive bias that lead them to overemphasize extrinsic factors (e.g. job security, and money) with employees, whereas employees were actually more interested in intrinsic factors (e.g. meaningful work, and growth). Such misaligned offers fail to stimulate desired forms of employee behavior that are central to enriching the competitive advantage of the organization (Osterloh, Frost \& Frey, 2002). Therefore, erroneous motivation beliefs may impose additional and unnecessary economic costs on organizations without having stimulated either employee performance or output.

Erroneous motivation assumptions and the extrinsic incentive bias hint that the lay theories held by managers contain combinations of theoretically contradictory motivation beliefs drawn from multiple theories. For example, both the Heath (1999) and Kovach (1987) studies show that managers erroneously attribute extrinsic motivation to employees while employees report more internal and meaning-based reasons for their work. Managers did not attribute similar extrinsic motives to themselves, however. Instead, the managers claimed that they themselves were primarily motivated by meaningful work. Employees' beliefs about what motivated managers were similarly erroneous. Using a theory-based analysis, both managers and employees held tenets central to self-determination theory (subjective meaning) and reinforcement theory (extrinsic factors such as money) that they believed accurately explained their own and the other party's motivation, respectively. The accuracy of their beliefs about what motivated the other party were refuted by that party, however. This example of the seemingly functional yet erroneous combination of motivation beliefs from theories that strenuously contradict one another serves as a bridge between the lived experience of managers, the knowledge gap in the motivation literature, and the purpose of this study.

Because much confusion and overlap still exists in motivation definitions (Kleinginna \& Kleinginna, 1981) and constructs (Mayer, Faber, \& Xu, 2007) one might reasonably argue that managers' erroneous assumptions about what motivates employees are to be expected. For example, belief in the immediate and long-term effectiveness of extrinsic incentives (e.g. compensation, and reward and recognition) to stimulate positive motivational responses - central tenets of reinforcement theory - is a mainstay of present day organizational systems (Stone, Deci, \& Ryan, 2009). But, more contemporary motivation theory vigorously challenges reinforcement theory's assertions in the work setting (Deci, Koestner, \& Ryan, 1999). Furthermore, discerning the internal structure of the multiple motivation beliefs individuals combine in their private lay theories can be challenging because the many beliefs are often implicit, unconscious, and contradictory. One way to begin to discern or "unpack" the internal content and structure of managers' motivation beliefs is to use empirically valid theory as a guide.

\subsection{Purpose of the Study and Research Question}

The present study centered on the question, to what extent can a valid, reliable, brief, and multiple theory-based self-report instrument be created to measure a manager's beliefs about what motivates employees? Answering that question is complicated by the multitude of empirical frameworks from which practicing managers and researchers might draw their beliefs about motivation, and the plethora of non-empirical ideas in everyday use in organizations (Van Nuland, Dusseldorp, Martens, \& Boekaerts, 2010). The following review of the literature explains the rationale behind the choice of four empirically valid motivation theories: Reinforcement theory (RT; Skinner, 1974), expectancy valence theory (EVT; Vroom, 1995), achievement motivation theory (AMT; McClelland, 1987), and self-determination theory (SDT; Deci \& Ryan, 1985).

\subsection{Review of Literature}

The four selected theories parsimoniously represent motivation science across human experience and beyond the domain of work. From a theory-across-time perspective, RT, EVT, AMT, and SDT span the field of motivation science from early in 20th century to present day (Reeve, 2009). Based also on our professional experience consulting to leaders in organizations worldwide, managers' beliefs related to the included theories are often linked to organizational systems intended to foster or alter employee motivation. While the present study did not attempt to be inclusive of all motivation theory, it is felt the four included theories set a solid foundation to begin the exploration of the content and structure of manager motivation beliefs by constructing a valid and reliable survey instrument. It may now be useful to provide an overview of each of the four theories with particular emphasis on how they relate to work today. 


\subsubsection{Reinforcement Theory}

Reinforcement theory (Skinner, 1974) continues to strongly influence management practice and organizational systems. Central RT tenets such as the identification and careful timing of contingent rewards, and the use of positive and negative reinforcements as necessary preconditions for an organism to act in a desired way continue to inform compensation, reward and recognition, and performance management systems (Condly, Clark, \& Stolovitch, 2003). Despite being prevalent, though, practitioners are ambivalent about the effects of RT-based processes on decision quality. For example, adding to the broader debate among some business scholars about management's limited interpretation and application of social science and economic theory (Ghoshal, 2005; Pfeffer, 2005), executives from a high profile management consulting firm (Dewhurst, Guthridge, \& Mohr, 2010) lamented the recent reintroduction of the same type of pay-for-performance bonus plans that helped fuel the global economic downturn a short time earlier. Similarly, researchers continue to debate the influence of RT principles at the level of the firm and macro-economy. While they also continue to examine the psychological processes (Podsakoff, Bommer, Podsakoff, \& MacKenzie, 2003) and workplace performance outcomes related to central RT principles (Fang \& Gerhart, 2012; Cameron \& Pierce, 1994; Ryan \& Deci, 1996; Deci, Koestner, \& Ryan, 1999), a meta-analysis of 45 studies culled from a pool of 600 confirmed the positive effects of RT-based incentives on work performance (Condly, Clark, \& Stolovitch, 2003). The ongoing discourse about RT principles among researchers and practitioners, alike, speaks to their prominence in management praxis today, and so RT was included in the proposed instrument.

\subsubsection{Expectancy Valence Theory}

Expectancy valence theory —often called expectancy theory and valence instrumentality expectancy theory—placed the incentives that reinforcement theorists propose determine human action into a more complex system that included cognitions. Expectancy valence theory was made possible because of the cognitive revolution in psychology (Shah \& Gardner, 2008). The "mentalisms" that Skinner (1974) maintained had no relevance in the system of human behavior - such as affect, thought, attention, and intention-were put at the very heart of the exploration of what caused human beings to make conscious, and not merely reflexive, decisions to engage in purposive behavior (Shah \& Gardner, 2008, p. 14). Because EVT was originally conceived to refer to workplace behavior, it was quickly influential with organizational development researchers and management practitioners (Locke, 1975).

Expectancy valence theory did not replace reinforcement theory however, any more than a new theory typically supplants its predecessors upon inception (Markóczy \& Deeds, 2009). Instead, expectancy theorists still saw the relevance of incentives to action, but only as the individual perceived them. Individual action amidst external conditions was theorized to be not a deterministic and easily controlled response to those conditions, but rather the result of one's subjective experience and appraisals of such conditions.

In EVT, individual motivation was conceptualized as choiceful behavior based on a multiplicative function of three variables: valence, instrumentality, and expectancy (Vroom, 1995). Valence is the emotional desirability, attractiveness, and anticipated satisfaction of a particular outcome (Van Eerde \& Thierry, 1996). When managers take an interest in whether an employee wants to take on a role project, or task, they consider the valence that task has to the employee.

Based on Vroom's (1995) original conceptualization, instrumentality and expectancy are less clear than valence, and are easily confused - and are equally central to the decisions employees make. Expectancy valence theory sees the individual, say, a manager, as making estimates of the likelihood that the action he or she is considering in the current moment will bring about a desired outcome at a future moment. The estimates include two types of outcomes, one following close in time from the initial action, and another occurring at some later time. The estimates that an action will lead to an intermediate outcome or to an outcome later in time are termed instrumentality and expectancy, respectively. For the remainder of this paper, though, we will use the term expectancy, since it is closest to the everyday language of managers who want to know what they can expect to result from their actions and what they can predict - or expect - an employee to do. Indeed, managerial work is an ongoing attempt to maximize the probability that actions contemplated or taken in the present moment will deliver desired results in the future. Such calculations lie at the heart of all manner of organizational decisions, such as how much to spend on research and development, whether to enter a new market, and whether to hire —or fire-an employee.

The important contribution of EVT to our understanding of human motivation is its prediction that people choose to engage and persist in a task or goal based on how they feel about a potential final outcome (an end) and the steps needed to achieve it (the means), and their estimate of the likelihood that the means will generate the desired end. 
While EVT proposed individuals act toward valued goals based on a subjective calculus of valence, instrumentality, and expectancy, others proposed people act based on a configuration of psychological needs.

\subsubsection{Achievement Motivation Theory}

Building on Atkinson's (1978) work, and Murray's much earlier (1938), McClelland (1987) surmised that the extent of an individual's striving for particular outcomes - a central problem of motivation - can be explained by the extent to which a trichotomy of psychological needs for achievement (nAch), affiliation (nAff), and power (nPow; Pinder, 2008) are aroused. McClelland proposed that such needs are universal to the human condition, acquired in early childhood via socialization, and are rooted in the unconscious. The nAch is defined as the need to do something that demonstrates personal mastery. People high in nAch were predicted to engage in work that required planning, creativity, and persistence in order to achieve valued outcomes (McClelland, Clark, Roby, \& Atkinson, 1958). The need for affiliation, nAff, refers to pleasing others and gaining their approval, while the need for power, nPow, refers to the need to influence and have an impact on others (Reeve, 2009). Taken together, AMT aimed to measure "the achievement motive". In addition to managerial success (McClelland \& Boyatzis, 1982), a main focus of AMT was societal economic achievement (McClelland \& Winter, 1969). In its early days, AMT theorists also encouraged practicing managers to use nAch measures to improve management decisions such as those related to personnel and hiring (McClelland, 1967).

In AMT, the social context is said to "trigger" behavior that aims to achieve valued outcomes based on an individual's relative configuration of nAch, nAff, and, nPow (McClelland, 1987). In that way, AMT joins with expectancy theory to predict that valence or subjective value assessed to various outcomes would also vary. By accounting for such variance, AMT can address a range of responses to everyday work phenomena, such as striving to surpass a previous performance standard and outcome goals (Locke \& Latham, 2006).

Today, AMT principles continue to influence management education and practice (e.g. McClelland \& Burnham, 2003; Arnolds \& Boshoff, 2003; Wheeler, Richey, Tokkman, \& Sablynski, 2006; van Emmerik, Gardner, Wendt, \& Fischer, 2010; Royle \& Hall, 2012). Indeed, striving toward goal achievement based on needs for achievement, affiliation, and power dovetails with the quotidian discussion of achievement, and also the mandates inherent to organizational work. We now turn to the fourth and final theory for inclusion in the instrument, self-determination theory (Deci \& Ryan, 2000).

\subsubsection{Self-Determination Theory}

As a meta-theory, SDT is arguably the broadest of the included theories, and has been validated in the work and organization domain (Gagné \& Deci, 2005). Self-determination theory continues the trend of social cognitive psychologists to elaborate explanations of what impels or inspires an individual to act within his or her environment. Self-determination theory proposes that individuals are naturally inclined to engage in and increase competence within their environments. This starting point sets SDT in opposition to reinforcement theory in that human functioning is said to be most positive when an individual acts voluntarily, optimistically, and feels free of coercion or control by outside forces - such as the incentives and punishments emphasized in RT (Deci \& Ryan, 2000). Such subjective feelings of freedom result from optimal satisfaction of one's basic psychological needs of autonomy, relatedness, and competence.

The SDT continuum considers autonomy the fulcrum of the subjective well-being analysis. Autonomy is the degree of perceived freedom from external control or coercion. Autonomy as conceived in SDT is the antithesis of the lack of freedom individuals have when presented with an external incentive as in reinforcement theory. Autonomy is highest in the intrinsic motivation state and lowest with external motivation.

As in AMT, SDT allows for attempts at satisfying relatedness needs from a deficit-based avoidance of rejection. Like some formulations of AMT, SDT also allows for attempts to satisfy one's basic need for relatedness based on a healthier desire for commitment, intimacy, and vitality within relationships (Gaine \& La Guardia, 2009). The difference between those two possibilities results in a different motivational type on the continuum. Finally, competence is the desire to see oneself as - and to be-efficacious within one's environment. It is similar to Bandura's (1997) concept of self-efficacy.

Furthermore, SDT explicates four forms of extrinsic motivation: external, introjected, identified, and integrated (Sheldon \& Schachtman, 2007). External motivation is defined as acting based on an external inducement or reward. Introjected motivation refers to acting based on introjects, or feelings of guilt, shame, or fear, particularly with regard to important people and relationships. Identified motivation is characterized by action taken because the individual sees a meaningful relationship between the action and their personal goals. Integrated motivation is experienced 
when the action is deeply aligned with the individual's sense of self, or identity. Both the aligned and integrated forms of motivation are also characterized by not only a sense of engaging in activities freely, but also with sense of contribution to something beyond oneself (Gagné, 2003).

Taken together, the four forms of extrinsic motivation reveal the SDT proposition that there are many different ways an individual may experience the environment. Some of those ways are more positive than others. For example, an adult employee acting based on the experience of introjected motivation has a less positive, less optimistic experience than one whose motivation is of the integrated variety. All forms of motivation hypothesized by SDT align along a continuum in a simplex-like pattern (Gutman, 1955), which means each motivation type correlates most positively with those adjacent to it, with each motivation type declining in relative subjective well-being with distance from intrinsic motivation. This elaborated explanation that includes motivation type, quality, and both self-concordant and pro-social reasons for participating in a task, goal, or situation is arguably SDT's most significant contribution to motivation psychology.

After selecting the four theories included in the proposed instrument, the instrumentation currently available within each theoretical framework was closely examined. A recent review of the instruments available confirmed that motivation beliefs remain little explored. Based on that review, we know of no empirical instruments that assess motivation beliefs in the manner undertaken here.

The review of relevant motivation instruments was also useful for writing the items for the proposed instrument. For space considerations, the instrumentation literature review - which includes a detailed analysis of each instrument's items - can be perused elsewhere (Facer, 2012). The following section details the process by which the proposed instrument — the Motivation Beliefs Inventory (MBI) — was created and validated.

\section{Method}

Two studies using two samples were conducted to create and validate the Motivation Beliefs Inventory. Study 1 was used to create the initial item set and establish its factor structure. Study 2 confirmed the initial factor structure. Using a refined item set, Study 2 also established construct and discriminant validity, and offered initial evidence of convergent validity. The two studies were conducted over a six month period. Each study is described in detail below.

\subsection{Study 1}

\subsubsection{Subconstructs and Item Creation}

Developing a survey instrument first required the identification and selection of relevant subconstructs within each theory. A comprehensive review of the motivation literature revealed several subconstructs within each theory that the items were written to represent (Table 1). After appropriate items were written, they were vetted by a group of motivation scholars to ensure accurate presentation of each theory's central tenets. The experts included three motivation researchers, including one from a European university. In particular, items were evaluated to ensure they represented aspects of a single theory and, at the level of face validity, avoided conceptual overlap across theories. Careful refinement of item wording was essential since some subconstructs are similar across multiple theories, for example, the need for relatedness in SDT and the need for affiliation in AMT. Based on the experts' analysis, items were further refined or eliminated, and additional items were written and vetted using the same process. The final item sets were then distributed to the database of potential respondents twice. Study 1 was conducted to test the anticipated four factor structure with an initial item pool. Study 2 confirmed the factor structure from Study 1 using the expanded item pool. Discriminant validity was tested, and evidence of convergent validity was examined. The specific methods used in each study will now be explained. 
Table 1. Theories and subconstructs in the item pools for the Motivation Beliefs Inventory

\begin{tabular}{lll}
\hline \multicolumn{1}{c}{ Theory } & & \multicolumn{1}{c}{ Construct } \\
\hline Reinforcement (RT) & $\circ$ & Use of rewards and/or incentives \\
& $\circ$ & Use of punishment \\
& $\circ$ & Impact of rewards and/or incentives \\
& $\circ$ & Impact of withholding rewards and/or punishment \\
\hline Expectancy Valence & $\circ$ & Expectancy or probability of success \\
(EVT) & $\circ$ & Valence of outcomes \\
& $\circ$ & Instrumentality of means to valued ends \\
& $\circ$ & Commitment to means to valued ends \\
\hline Achievement Motivation & $\circ$ & Socialized needs for achievement, affiliation, and power \\
(AMT) & $\circ$ & Striving to achieve something novel or record-breaking \\
& $\circ$ & Challenge level of a goal \\
& $\circ$ & Competing to win \\
\hline Self-Determination & $\circ$ & Basic psychological needs for autonomy, relatedness, and competence that \\
(SDT) & & combine to form six motivation types \\
& $\circ$ & Impact of pressure on motivation \\
& $\circ$ & Six motivational types: amotivation, external, introjected, identified, \\
& & integrated, and intrinsic \\
& $\circ$ & Contribution to welfare of the whole \\
& $\circ$ & Integrated motivation and pro-social ends \\
& &
\end{tabular}

\subsubsection{Participants}

Data for both studies were collected from a convenience sample of members of a global consulting company based in the western United States. The database included customers and non-customers, and both managers and non-managers who had voluntarily agreed to be contacted. The manager category included someone to whom another individual or group of direct reports. From a title standpoint, the manager category includes positions such as supervisor, manager, and executive, while the non-manager category included employees with no direct reports.

\subsubsection{Sample Selection and Power}

Study participants received an email invitation to the survey that briefly explained the purpose of the survey, offered instructions for participation, and provided an electronic link that opened the survey. All surveys were completed electronically. In addition to the initial distribution of the MBI, some recipients forwarded the survey to colleagues and other business professionals known either personally or through their professional networks. The number of additional participants obtained from such secondary distributions is thought to be negligible. Sample size adequacy was tested using Costello and Osborne's (2005) standards.

Based on comparing the number of completed instruments received to the number of items in the version of the MBI presented to respondents, it was decided to drop partially completed surveys from analysis. More specifically, because the number of completed instruments resulted in a sample size to item (SSIR) ratio - a measure of sample adequacy commonly used in factor analytic research - at the upper end of the acceptable range (Costello \& Osborne, 2005), no imputation of missing data was necessary for partially completed surveys. While the SSIR is far from a firm standard (Velicer \& Faya, 1998) according to a recent literature review of more than 300 exploratory factor analytic studies (Costello \& Osborne, 2005), only 21\% achieved a sample size to item ratio greater or equal to 20:1. The 20:1 ratio was targeted for both Study 1 and Study 2.

\subsubsection{Principal Components Analysis}

Data collected were subjected to principal components analysis (PCA), an analytical technique that allows for the separation and reduction of a set of items into a smaller number of differentiated and uncorrelated clusters (Vogt, 2005). Individual items are said to "load on" a cluster based on how well they correlate with each other but not with 
other items. The orthogonal clusters represent items that together correspond with a given psychological construct. As such, PCA is a means of establishing construct validity.

Central to PCA is the issue of data reduction (Hinkle, Wiersma, \& Jurs, 2003). The decision to eliminate items is based on analysis of the item strength and intercorrelations between variables (Fink, 2003), both of which are indicated by coefficient alphas. There are no emphatic standards for item alphas. Instead, there are general guidelines (e.g., Clark \& Watson, 1995; Cortina, 1993; Schmitt, 1996). Using such guidelines, a minimum acceptable item alpha was set at .5.

Principal component analysis and other statistical tests were conducted using Statistical Package for Social Sciences (SPSS) software, version 19. The question of how many factors to retain in a PCA analysis is among the most important decisions facing researchers (Hayton, Allen, \& Scarpello, 2004). To answer that question, maximize inferential robustness, and more pointedly, to simultaneously minimize the inferential risks associated with the standard eigenvalue $>1$ decision rule for factor extraction (Costello \& Osborne, 2005), a secondary check on the factor structure, parallel analysis (PA) was also conducted in Study 2.

\subsubsection{Item Retention and Elimination}

In keeping with best practice, items were retained from Study 1 for further testing in Study 2 through an iterative process of elimination (Clark \& Watson, 1995). For example, items that cross-loaded on more than one factor at a similar and high alpha level were eliminated. Those items did not sufficiently differentiate between dimensions of multiple theories - and did not clearly distinguish a dimension of the single theory for which the items were originally written. Individual item alpha scores are a measure of item reliability, and help answer the question, "Does this item clearly and reliably relate to a single construct?" While cross-loading is not ideal, it is often a reality, particularly when dimensions of constructs one is attempting to differentiate - in this case, whole motivation theories - are conceptually similar (Ferguson \& Cox, 1993). The test for retaining an item that cross-loads on multiple factors, then, is determined by whether it correlated more strongly with one factor than the others (Clark \& Watson, 1995). No universal decision rules about the optimal magnitude of the difference between strong and relatively weaker loadings have been agreed upon by researchers, though Ferguson and Cox's (1993) suggested differential of $\geq .20$ was used in this study. Even if it loaded more weakly on a second factor that contains items with which it aligns better conceptually, however, it is still a candidate for deletion (Clark \& Watson, 1995, p. 317).

\subsubsection{Factor Reliability}

After the item set was refined using PCA (and parallel analysis after Study 2, as described below), a Cronbach alpha (Cronbach, 1951) analysis was performed to determine the inferential robustness of each remaining set of clustered questions. Cronbach alpha is a measure of how well a number of items together represent a given construct (McGrath, 2005), and is often reported on both item and factor levels. Despite some debate (Bernardi, 1994), it is generally accepted that an alpha score of .70 is the lower limit of acceptability, though scores approaching .80 are preferred (Nunnally, 1978). While alpha scores can range from zero to one, .70 was set as the internal consistency target for each factor in this study. For the total instrument, an alpha coefficient of .80 was targeted.

\subsection{Additional Methods in Study 2}

In addition to the above steps, additional analyses were conducted in Study 2. These included parallel analysis, and analysis of both discriminant and convergent validity.

\subsubsection{Parallel Analysis}

The factor structure confirmed using the eigenvalue $>1$ standard in Study 1 was further scrutinized in Study 2 using parallel analysis (PA). Parallel analysis helps researchers decide on the maximum number of factors to extract from the data based on the scree test (Crawford et al., 2010). Parallel analysis has been shown to be one of the most accurate methods of determining the number of latent factors indicated by the data (Reise, Waller, \& Comrey, 2000).

\subsubsection{Discriminant Validity}

Once it appeared a final set of items from Study 1 coalesced into subscales with acceptable properties, the subscales were tested for discriminant validity using the Beliefs about Well-Being Scale (McMahan \& Estes, 2010, p. 267). Discriminant validity acts as a negative check of whether an instrument measures what it says it measures by making sure it does not measure a construct from which it is hypothesized to be theoretically distinct (Anastasi, 1976). The accepted .85 criterion (Campbell, 1960) was used to test the discriminant validity of the MBI subscales.

The BWBS was relevant for several reasons. The first is that, like the many instruments discussed in the literature review, the BWBS and its individual items are not about motivation beliefs. Instead, the BWBS measures beliefs 
about one's well-being using four subconstructs. They are the experience of pleasure (EP), absence of negative affect (ANE), self-development (SD), and contribution to others (CO; McMahan \& Estes, 2010, p. 267). Furthermore, like the concept of motivation, the concept of well-being is relatable to everyday experience. More importantly, though, well-being - and its BWBS subconstructs - are often anecdotally related to motivation. It is common for individuals, for example, to talk about their motivation in terms of "how thing are going generally." It is also common in everyday life to define one's sense of psychological well-being in the moment in terms of one's affect, or the presence or absence of negative emotions, situations, or issues (Deiner, Suh, Lucas, \& Smith, 1999). At work, too, it is common for people to question whether the small tasks they are required to perform will help them develop new skills, or if such tasks contribute to something bigger or more meaningful - two of the four dimensions of well-being validated in the BWBS.

From an empirical standpoint, too, the construct of subjective well-being is relevant because it is associated with and yet distinct from motivation. Self-determination theory, for example, proposes that one's subjective well-being results from the extent to which one's innate psychological needs for autonomy, relatedness, and competence are satisfied (Deci \& Ryan, 2000). Furthermore, SDT proposes that the more intrinsically motivated an individual is-or the extent to which they naturally enjoy the activity in which they engage - the greater their sense of vitality and well-being. The relationship of well-being to motivation is relevant beyond SDT, however. Indeed, Vroom (1995) said that were he to conceptualize EVT today - decades after his original presentation - he would include intrinsic motivation as conceived by SDT researchers - which includes the dimension of subjective well-being. As such, Vroom, viewed well-being as related not only to self-determination concepts of motivation, but also to the expectancy valence dimensions of motivation.

\section{Results}

The 20-item Motivation Beliefs Inventory employs a 6-point Likert-type scale which allows respondents to report their level of agreement with each motivation belief statement using the following categories: Strongly disagree, somewhat disagree, disagree, agree, somewhat agree, and strongly agree. The final instrument contains 20 items, five for each of the four subscales.

\subsection{Participant Demographics}

Fortunately, the demographics for respondents in both Studies 1 and 2 were similar. For example, in Study 1 the typical respondent was Caucasian (80\%), female (59\%), and a manager (73\%). From an education standpoint, 20\% had completed high school or some college, while $38 \%$ had achieved an undergraduate degree and 559 (42\%) held graduate degrees. Despite the smaller sample size in Study 2, the demographics for respondents were similar. Of the 712 respondents, $73 \%$ were managers, $56 \%$ were female, $85 \%$ were white/Caucasian, and $44 \%$ held graduate degrees.

\subsection{Study 1}

\subsubsection{Sample Adequacy}

In this study, sample size adequacy was evaluated against the rating scale of Comrey and Lee (MacCallum, Widaman, Zhang, \& Hong, 1999). A total of 1627 surveys were opened and fully completed surveys were received from 1,322 participants. Based on a ratio of completed instruments received to the number of items in the instrument, it was decided to drop partially completed surveys from analysis. The initial item set contained 28 items, seven for each motivation theory. An SSIR (Velicer \& Faya, 1998) of 47:1 was achieved, which is considered excellent (Hinkle \& Oliver, 1983). The dataset was deemed appropriate for PCA based on both a strong KMO statistic and significant Bartlett's Test of Sphericity (Dziuban \& Shirkey, 1974).

\subsubsection{Data Analysis}

Principal components analysis (PCA) was conducted to determine the underlying factor structures of the 28 items and five demographics questions in Study 1. Participants were asked to rate their agreement with each belief statement on a six-point Likert-type scale from strongly disagree to strongly agree. In Study 1, 28 items were presented to participants along with the five demographic questions regarding gender, work role, ethnicity, birth year, and education level.

The number of interpretable factors was based on eigenvalues greater than one, using Varimax rotation, and a maximum of 50 rotations. The data strongly suggested a four factor structure. Based on analysis of item alphas and the resulting Cronbach alpha scores for the four, four-item factors they formed, 16 items were retained for Study 2. 
The results of the principal component analysis for Study 1 yielded four subscales with four items each. Table 2 shows the factor loads for the rotated component matrix. In three of the factors, items loaded at a level of . 6 or higher. The fourth factor items loaded between .51 and .72. Table 2 shows the eigenvalues and variance statistics for each of the four factors, including the amount of variance explained.

The Varimax rotation method reported here is arguably the most common rotation method used in psychometric research (Costello \& Osborne, 2005), and it is commonly asserted that different rotation methods did not produce strikingly different results. Nonetheless, to ensure the factor structure did not depend upon the selection of rotation method, the data was also subjected to an oblique rotation method. No notable differences in item alpha levels or in factor loadings resulted from the change of rotation method. The correlation matrix using Varimax rotation revealed item alphas as follows: RT: .7-.8; EVT: .54-.77; AMT: .6-.69; SDT: .53-.72. The rotation converged in five iterations.

Table 2. Factor eigenvalues greater than one in Study 1

\begin{tabular}{lrrr}
\hline Factor Number & Eigenvalue & \% of Variance & $\begin{array}{l}\text { Cumulative \% } \\
\text { of Variance }\end{array}$ \\
\hline 1 & 3.33 & 20.83 & 20.83 \\
2 & 2.37 & 14.78 & 35.60 \\
3 & 1.25 & 7.83 & 43.43 \\
4 & 1.03 & 6.44 & 49.88 \\
\hline
\end{tabular}

\subsection{Study 2}

\subsubsection{Sample Adequacy}

In Study 2, the SSIR dropped to 17:1 due to an increased item set (42) and a smaller final sample size (712). In Study 2, 605 completed instruments were returned. To achieve a higher SSIR ratio, and thus maximize inferential robustness, another 107 were adjusted for minimal amounts of missing data by using the mean value in place of the missing observations, resulting in a total of sample size of 712. Despite the SSIR decrease, the ratio was still greater than the ratios reported in nearly two thirds of the studies reviewed by Costello and Osborne (2005). The KMO statistic for the dataset in Study 2 was an excellent .81, and the Bartlett's statistic was significant at .01.

\subsubsection{Data Analysis}

Principal components analysis was conducted to determine the underlying factor structures of the 42 items and five demographics questions in Study 2. Recall that participants were asked to rate their agreement with each belief statement on a six point Likert-type scale from strongly disagree to strongly agree. In Study 1, 28 items were presented to participants along with the five demographic questions regarding gender, work role, ethnicity, birth year, and education level. In Study 2, 42 theory items were presented to respondents with the same demographic questions as in Study 1, 16 of which were retained from Study 1.

\subsubsection{Item Retention and Elimination}

In keeping with best practice, the 16 retained items were chosen through an iterative process of elimination (Clark \& Watson, 1995). Items that cross-loaded on more than one factor at a similar and high alpha level were eliminated, as those items did not sufficiently differentiate between dimensions of multiple theories - and did not clearly distinguish a dimension of the single theory for which the items were originally written. For both Studies 1 and 2, the reliability coefficient goal to retain items was set at .50 , with a target differential for any cross-loading on multiple factors of $\geq .20$. Items in Studies 1 and 2 satisfied these conditions.

\subsubsection{Principal Components Analysis}

A PCA was conducted in Study 2 using methods similar to those used for Study 1, with some noteworthy exceptions. In order to improve the psychometric properties of the instrument, it was necessary to expand the item set in Study 2 beyond the 16 items retained from Study 1. The 26 items added in Study 2 brought the number of items included in Study 2 to 42 . In addition to the expansion of the item pool, parallel and discriminant validity analyses were conducted.

The eigenvalues for the four factors are indicated in Table 3. In Study 2, the total variance explained improved by approximately $10 \%$. Figure 1 shows that parallel analysis confirmed the anticipated four-factor structure. Table 4 shows the rotated correlation matrix. 
Table 3. Factor eigenvalues greater than one in Study 2

\begin{tabular}{lccc}
\hline Factor & Eigenvalue & \% of Variance & $\begin{array}{l}\text { Cumulative \% } \\
\text { of Variance }\end{array}$ \\
\hline (1) AMT & 4.39 & 21.93 & 21.93 \\
(2) RT & 2.94 & 14.69 & 36.62 \\
(3) SDT & 2.12 & 10.57 & 47.19 \\
(4) EVT & 1.50 & 7.51 & 54.70 \\
\hline
\end{tabular}

\subsubsection{Parallel Analysis}

A secondary check on the factor structure indicated by PCA — parallel analysis — was also conducted in Study 2. Parallel analysis helps discern the maximum number of factors to extract based on the scree test (Crawford et al., 2010). While it is prone to overestimating the number of factors, or components to retain (Zwick \& Verlicer, 1986), PA has been shown to be one of the most accurate methods of determining the number of latent factors indicated by the data (Reise, Waller, \& Comrey, 2000). Simply stated, parallel analysis works by creating a random dataset with the same number of cases and variables as the original dataset. Eigenvalues for the comparison dataset are generated. Components from the original dataset are retained when the eigenvalues for the components in the original dataset exceed those of the comparison dataset.

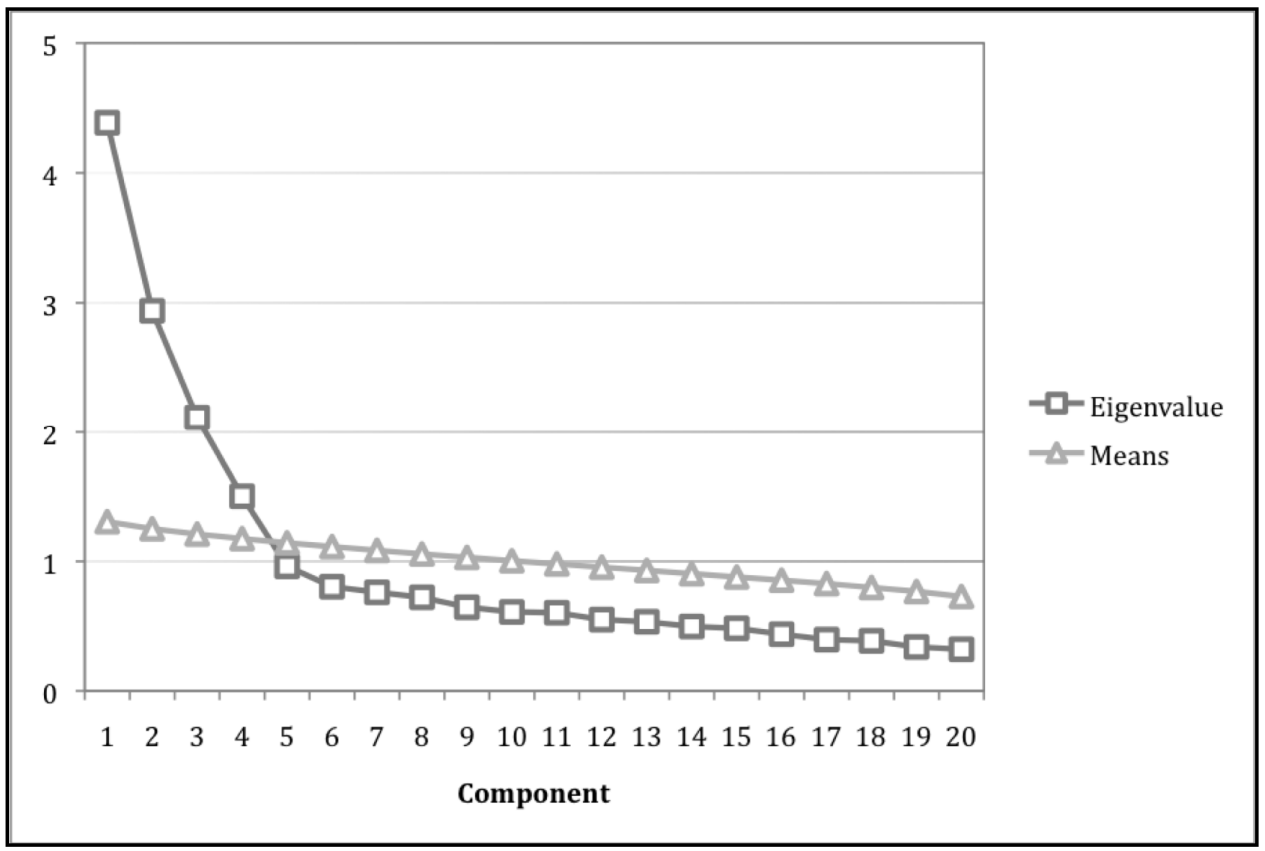

Figure 1. Parallel analysis scree plot in Study 2

Once a four-factor structure was confirmed, the reliability of each factor was analyzed. The internal consistency of each subscale as measured by Cronbach alphas for all subscales was acceptable; specifically, the alphas for the AMT, RT, and SDT subscales showed high internal consistency, at .82, .77, and .77, respectively, while the EVT subscale demonstrated an acceptable level of .71. Importantly, for all four subscales the alphas were significantly higher in Study 2 than they were in Study 1.

An additional check of the construct validity based on subscale correlations was performed. The correlations between subscales shown in Table 4 were acceptably low. The correlation between the RT and SDT subscales was low and in the anticipated negative direction. This latter finding lends credibility to the construct validity of the instrument as prior SDT research has shown (e.g., Deci et al., 2001; Roth \& Assor, 2010; Williams et al., 2006) negative correlations with reinforcement theory constructs such as external rewards, contingent incentives, and pressure and control, and intrinsic motivation. All such correlations in the present study were significant at the .01 level. 
Table 4. Cronbach alpha coefficients and subscale correlations in final Motivation Beliefs Inventory

\begin{tabular}{|c|c|c|c|c|}
\hline \multirow[b]{2}{*}{ Item } & \multicolumn{4}{|c|}{ Theory } \\
\hline & AMT & RT & SDT & EVT \\
\hline amt28 & .74 & & & \\
\hline amt29 & .78 & & & \\
\hline amt30 & .73 & & & \\
\hline amt33 & .75 & & & \\
\hline amt34 & .75 & & & \\
\hline $\mathrm{rt} 1$ & & .83 & & \\
\hline $\mathrm{rt} 2$ & & .81 & & \\
\hline $\mathrm{rt} 3$ & & .72 & & \\
\hline $\mathrm{rt} 4$ & & .66 & & \\
\hline $\mathrm{rt19}$ & & .60 & & \\
\hline evt6 & & & .53 & \\
\hline evt7 & & & .73 & \\
\hline evt8 & & & .77 & \\
\hline evt26 & & & .75 & \\
\hline evt27 & & & .63 & \\
\hline sdt16 & & & & .76 \\
\hline sdt37 & & & & .79 \\
\hline sdt38 & & & & .69 \\
\hline sdt39 & & & & .57 \\
\hline sdt 40 & & & & .54 \\
\hline AMT & 1.00 & & & \\
\hline $\mathrm{RT}$ & .11 & 1.00 & & \\
\hline SDT & .45 & -.10 & 1.00 & \\
\hline EVT & .26 & .16 & .32 & 1.00 \\
\hline
\end{tabular}

\subsection{Discriminant Validity}

After establishing the construct validity of the MBI via principal components and parallel analyses, the instrument was tested for discriminant validity. Discriminant validity scrutinizes whether an instrument measures what it attempts to measure by making sure it does not measure - or diverges from - what it is not trying to measure. In both Studies 1 and 2, a set of items was included to establish that the MBI measured beliefs about motivation and not another set of beliefs. The Beliefs about Well-being Scale (BWBS; McMahan \& Estes, 2010) was used to establish discriminant validity. The advantages of the BWBS scale are several, including that it has demonstrated acceptable psychometric properties, is available in its entirety, is current, and is about beliefs.

Table 5 shows the correlations between MBI subscales and the four subscales of the BWBS. Discriminant validity correlation levels, which range between zero and one, are said to be acceptable in the range below .85 (Campbell \& Fiske, 1959). Discriminant validity was established using the Campbell and Fiske formula that adjusts for measurement error, and revealed that for the MBI, all but one subscale correlation remained within acceptable levels. 
Table 5. Discriminant validity with BWBS subscales in Study $2(\mathrm{n}=712)$

\begin{tabular}{|c|c|c|c|c|}
\hline \multirow[b]{2}{*}{ BWBS Subscales } & \multicolumn{4}{|c|}{ MBI Subscales } \\
\hline & AMT & RT & SDT & EVT \\
\hline Experience of Pleasure & .15 & .40 & .12 & .15 \\
\hline Avoidance of Negative Experience & .40 & .24 & .49 & .70 \\
\hline Self-Development & .34 & .10 & .58 & .97 \\
\hline Contribution to Others & .33 & .36 & .35 & .54 \\
\hline
\end{tabular}

\section{Discussion and Implications}

The purpose of this study was to create and validate an instrument to help leaders become more cognizant of what they believe about employee motivation, and do so using several valid motivation theories. This is the first study to measure managers' motivation beliefs in such a way. The Motivation Beliefs Inventory was created and validated using data from two large samples of businesspeople drawn from the database of a U.S.-based leadership training company. The findings from two studies conducted several months apart indicate that the MBI successfully delineates four subscales, with five items per subscale and each subscale representing a single motivation theory. (Appendix A). The anticipated four factor structure was revealed using principal component analysis. Each factor demonstrated acceptable validity (Reise et al., 2000), and the four-factor structure was verified using parallel analysis. The final structure demonstrated acceptable internal consistency with subscale alpha coefficients ranging from .71 to .82 . The Cronbach alpha for the entire instrument is .77 , indicating an acceptable and moderately high degree of reliability. The results of this study indicate that the instrument successfully factored motivation beliefs using a brief set of items reflecting core constructs of four theories. This result provides a positive response to the research question.

The inspiration for this study is that it is useful for leaders to be aware of the assumptions underlying their actions. This idea is not new. Psychologists and organization researchers have said for decades that behavior is based on beliefs (e.g. Lewin, 2008; Senge, 1990; Doyle \& Ford, 1995). Motivation psychologists have echoed that assertion as it relates specifically to motivation in the workplace (e.g. McGregor, 1960; Levinson, 1973; Heath, 1999) In practice, though, leaders continue to be perplexed by the question of how to motivate employees (Herzberg, 1987). Nonetheless, despite that the answer to a manager's question, "how do I motivate employees" would be based on the manager's beliefs, scholars have focused little attention on what those beliefs might be. Instead, much contemporary motivation research has focused on measuring an individual's motivation in response to an intervention (often short-term), or a survey that asked what his or her experience was when recalling a specific setting or situation. But, as was asserted earlier, measuring an individual's motivational response does not reveal what that individual already believes motivates him or herself, or someone else. In this way, researchers come to know little about the individual's present thoughts about how motivation works, or what best motivates oneself or others. Consequently, measuring a manager's motivational response in such studies may be a poor predictor of what that manager would then do "to motivate" an employee in the course of real work.

Responding to this gap in the literature, the Motivation Beliefs Inventory allows for a systematic, theory-based "unpacking" of the motivation beliefs held by leaders. This is an important contribution to the field in that the MBI would allow motivation beliefs to be explored, and to be explored without the constraints imposed by single theories. A thorough review of the literature confirmed that the majority of motivation research is conducted within a single theoretical framework. But, the lived experience of individuals at work — or anywhere — is less tightly contained, and so a wider perspective is needed.

Some limitations of the present research are important to note. First, while data were collected from large samples of businesspeople, the database was owned by a consulting company whose business is primarily in the United States. Furthermore, the sample was primarily white/Caucasian and so additional validation work is needed using a more diverse sample. The data were also cross-sectional self-report data, some limitations of which were discussed earlier. Further test-retest validation would be helpful. Convergent validity was not tested, as there appears to be no other instruments related to motivation beliefs. Additional validation would be beneficial as and when more motivation beliefs instruments become available. Finally, the MBI subscales do not represent every dimension of their respective theories. A larger item pool would allow for wider sub-construct inclusion and further strengthen the explanatory power of the instrument. 


\subsection{Conscious Examination of Beliefs}

Such limitations notwithstanding, the MBI is a useful initial step toward enabling leaders to consciously consider what they believe about what motivates employees. Such conscious examination joins calls from values researchers to examine beliefs more closely. For example, values researchers have long explored the distinctions between programmed and developed values (Rokeach \& Kliejunas, 1972). The main distinction between the two types is that developed values are sets of beliefs that have been freely and consciously chosen from a range of carefully considered alternatives. Both programmed and developed values share two characteristics that make loosening them and choosing different ones difficult; both types are highly prized and affirmed via behavior over time. Leaders may be especially unwillingly to challenge prized beliefs that lie at the root of their philosophy and practice of business no matter how beneficial researchers say it would be. For example, SDT research continues to assert the unintended negative consequences of extrinsic approaches to reward and recognition on both individual psychological health and task performance (Gagne \& Deci, 2005). This is arguably the most controversial aspect of SDT (Ryan \& Deci, 1996). However abundant the evidence, though, conscious examination of the motivation beliefs undergirding most reward and recognition systems in business is rare. One potent reason may be the dominant position neoclassical economic theory has in how business is conceptualized and managed by organizational leaders (Jensen \& Meckling, 1976), and taught in business schools by educators (Ghoshal, 2005).

Compounding the dominance of economic theory in business management and education is the psychologically intransigent nature of beliefs that are very deeply held. Research indicates that individuals who have the cognitive capacity to correctly interpret complex data that contradicts their historical beliefs related to an issue that is important to their sense of self, often incorrectly interpret that data so as to affirm their original beliefs (Kahan, 2013). Curiously, the more central the original beliefs are to the self, and the greater their cognitive capacity to interpret the complex and controversial data correctly, the more likely individuals are to bias their interpretation of the data so as to protect their self-view. In so doing, individuals protect against identity threat. It may be, then, that leaders' beliefs about the efficacy of reinforcement theory-based management techniques and systems are so firmly entrenched because they lie at the very core of who leaders perceive themselves to be, and therefore, what they as leaders, must, do. This hypothesis is not limited to reinforcement theory, though. The same might be said about common interpretations of AMT, for example, such as that competition and aggressive goals inevitably stimulate positive outcomes. Without such beliefs - and associated behaviors — would leaders even be leaders?

\subsection{Belief Intransigence}

Such "belief intransigence" means that even when the deeply held beliefs of intelligent people are erroneous, they are difficult to change. Recall that the beliefs managers hold about what motivates employees - and vice versa - are often wrong (Kovach, 1987) and biased toward an emphasis on extrinsic factors such as money (Heath, 1999). Heath went further and hypothesized that the extrinsic incentive bias is not specific to any one domain or authority-subordinate relationship, but is instead due to people generally formulating their own, incorrect, theories of motivation. Hence, business school educators and practitioners in human resources, organizational development, and management training who aspire to transform the practice of management using contemporary motivation research might do well to set conservative expectations about the likelihood and speed of belief and behavior change.

It would be unfair to suggest that only business leaders might be resistant to consciously examining their prized beliefs about what motivates employees. It is also possible that leaders in other forms of organization - such as government agencies and not-for-profit firms-would strenuously defend motivation beliefs that had proven insufficient at optimizing individual effort and organizational outcomes. For example, many non-business leaders strongly espouse not reinforcement theory principles, but more altruistic beliefs. Examples include doing work that is aligned with one's life purpose and the organization's service mission (i.e. beliefs more aligned with self-determination theory) rather than focusing on generating revenue or making a profit, or even competing with another service provider (i.e. an aspect of achievement motivation theory). Thus, consideration of "business" beliefs and approaches to employee motivation may still be resisted despite that most non-profit organizations struggle with insufficient funding to fulfill their missions, and government agencies are increasingly called to focus more on the profitability of their services in order to successfully compete with businesses.

Recognizing the link between strongly held beliefs and leader behavior, some scholars have urged leaders to openly examine their beliefs and mental models (Argyris, 1960; Forrester, 1961) as a necessary means to stimulating self-concordant goal achievement, organizational commitment (Bono \& Judge, 2003), and healthy organizational culture (Schein, 2004). Some have even chastised business leaders and educators for a persistent reliance on "asinine attitudes toward motivation" (Levinson, 1973), and "bad management theories" (Pfeffer, 2005) that are rooted in 
ideological interpretations of economic theory and biased assumptions about people and business (Ghoshal \& Moran, 1996). Such criticisms have been echoed by scholars who have explored the reasons that human resource practices are not evidence based (Lawler, 2007).

Despite that such criticisms have been little heeded, however, it is possible that leaders might welcome a thorough exploration of their underlying beliefs about what motivates employees. While it is common to hear stories of frustration, anxiety, confusion, and even anger that employees are not as motivated as they "should" be given the magnitude of the challenges their organizations face, and the importance of the work employees are responsible for, leaders also optimistically seek solutions that can help them achieve valued results. To this end, the Motivation Beliefs Inventory can help leaders take an important first step - to become aware of their own beliefs about employee motivation. With fresh awareness, they can then think "outside the box" of their current lay theories to consider more effective alternatives. They can explore the links and gaps between their beliefs (especially the erroneous ones), their behavioral integrity (Simons, 2002), and both the affect and behavior they have stimulated in employees. Leaders in any organization type can then better understand why their attempts to motivate employees do or do not catalyze and sustain intended behavior and results. Ultimately, leaders could then look more strategically at the theoretical premises upon which managerial behavior and the organization's motivational systems are based so as to better align them with approaches that contemporary research has shown are more likely to foster both employee well-being and organizational success.

\section{References}

Argyris, C. (1960). Understanding organisational behaviour. Homewood, Illinois: Dorsey Press.

Arnolds, C. A., \& Boshoff, C. (2003). The influence of McClelland's need satisfaction theory on employee job performance: A causal study. Journal of African Business, 4(3), 55-81. http://dx.doi.org/10.1300/J156v04n03_04

Atkinson, J. W. (1978). Introduction to motivation (2nd ed.). New York, NY: Van Nostrand.

Bandura, A. (1997). Self-efficacy: The exercise of self-control. New York, NY: W. H. Freeman and Company.

Bernardi, R. A. (1994). Validating research results when Cronbach's alpha is below .70: A methodological procedure. Educational \& Psychological Measurement, 54(3), 766. http://dx.doi.org/10.1177/0013164494054003023

Bono, J. E., \& Judge, T. A. (2003). Self-concordance at work: Toward understanding the motivational effects of transformational leaders. Academy of Management Journal, 46(5), 554-571. http://dx.doi.org/10.2307/30040649

Cameron, J., \& Pierce, W. D. (1994). Reinforcement, reward and intrinsic motivation: A meta-analysis. Review of Educational Research, 64, 363-423. http://dx.doi.org/10.3102/00346543064003363

Campbell, D. T., \& Fiske, D. W. (1959). Convergent and discriminant validation by the multilevel-multimethod matrix. Psychological Bulletin, 56, 82-105. http://dx.doi.org/10.1037/h0046016

Clark, L. A., \& Watson, D. (1995). Constructing validity: Basic issues in objective scale development. Psychological Assessment, 7(3), 309-319. http://dx.doi.org/10.1037//1040-3590.7.3.309

Condly, S. J., Clark, R. E., \& Stolovitch, H. D. (2003). The effects of incentives on workplace performance: A meta-analytic review of research studies. Performance Improvement Quarterly, 16(3), 46-63. http://dx.doi.org/10.1111/j.1937-8327.2003.tb00287

Cortina, J. M. (1993). What is coefficient alpha? An examination of theory and applications. Journal of Applied Psychology, 78(1), 98-104. http://dx.doi.org/10.1037/0021-9010.78.1.98

Costello, A. B., \& Osborne, J. W. (2005). Best practices in exploratory factor analysis: Four recommendations for getting the most from your analysis. Practical Assessment, Research \& Evaluation, 10(5), 1-9.

Crawford, A. V., Green, S. B., Levy, R., Lo, W., Scott, L., Svetina, D., \& Thompson, M. S. (2010). Evaluation of parallel analysis methods for determining the number of factors. Educational and Psychological Measurement, 70(6), 885-901. http://dx.doi.org/10.1177/0013164410379332

Cronbach, L. J. (1951). Coefficient alpha and the internal structure of tests. Psychometrika, 16, 297-334. http://dx.doi.org/10.1007/BF02310555

Deci, E. L., Koestner, R., \& Ryan, R. M. (1999). A meta-analytic review of experiments examining the effects of extrinsic rewards on intrinsic motivation. Psychological Bulletin, 125, 628-668. 
http://dx.doi.org/10.1037//0033-2909.125.6.627

Deci, E. L., \& Ryan, R. M. (1985). Intrinsic motivation and self-determination in human behavior. New York, NY: Plenum Press. http://dx.doi.org/10.1007/978-1-4899-2271-7

Deci, E. L., \& Ryan, R. M. (2000). The "what" and "why" of goal pursuits: Human needs and the self-determination of behavior. Psychological Inquiry, 11, 227-268. http://dx.doi.org/10.1207/S15327965PLI1104_01

Deci, E. L., Ryan, R. M., Gagné, M., Leone, D. R., Usunov, J., \& Kornazheva, B. P. (2001). Need satisfaction, motivation, and well-being in the work organizations of a former Eastern Bloc country: A cross-cultural study of self-determination. Personal and Social Psychology Bulletin, 27(8), 930-942. http://dx.doi.org/10.1177/0146167201278002

Deiner, E., Suh, E. M., Lucas, R. E., \& Smith, H. L. (1999). Subjective well-being: Three decades of progress. University of Illinois at Urbana-Champaign, 125(2), 276-302. http://dx.doi.org/10.1037//0033-2909.125.2.276

Dewhurst, M., Guthridge, M., \& Mohr, E. (2010). Motivating people: Getting beyond money. McKinsey Quarterly, 1, 12-15.

Doyle, J. K., \& Ford, D. N. (1995). Mental models concepts for system dynamics research. System Dynamics Review, 14(1), 3-29. http://dx.doi.org/10.1002/(SICI)1099-1727(199821)14:1<3::AID-SDR140>3.0.CO;2-K

Dziuban, C. D., \& Shirkey, E. C. (1974). When is a correlation matrix appropriate for factor analysis? Some decision rules. Psychological Bulletin, 81(6), 358-361. http://dx.doi.org/10.1037/h0036316

Facer, D. C., Jr. (2012). The Motivation Beliefs Inventory: Measuring motivation beliefs using four motivation theories. (Order No. 3528193, University of San Diego). ProQuest Dissertations and Theses, 153. [Online] Available: http://search.proquest.com/docview/1040884454?accountid=14742. (1040884454).

Fang, M., \& Gerhart, B. (2012). Does pay for performance diminish intrinsic interest? The International Journal of Human Resource Management, 23(6), 1176-1196. http://dx.doi.org/10.1080/09585192.2011.561227

Fink, A. (2003). The survey handbook (2nd ed.). Thousand Oaks, CA: Sage Publications.

Ferguson, E., \& Cox, T. (1993). Exploratory factor analysis: A users' guide. International Journal of Selection and Assessment, 1(2), 84-94. http://dx.doi.org/10.1111/j.1468-2389.1993.tb00092.x

Forrester, J. W. (1961). Counterintuitive behavior of social systems. In The collected papers of J. W. Forrester (pp. 211-244). Cambridge, MA: Wright-Allen Press. http://dx.doi.org/10.1177/003754977101600202

Gagné, M. (2003). The role of autonomy support and autonomy orientation in prosocial behavior engagement. Motivation \& Emotion, 27(3), 199-223. http://dx.doi.org/10.1023/A:1025007614869

Gagné, M., \& Deci, E. L. (2005). Self-determination theory and work motivation. Journal of Organizational Behavior, 26(4), 331-362. http://dx.doi.org/10.1002/job.322

Gaine, G. S., \& La Guardia, J. G. (2009). The unique contributions of motivations to maintain a relationship and motivations toward relational activities to relationship well-being. Motivation and Emotion, 33(2), 184-202. http://dx.doi.org/10.1007/s11031-009-9120-x

Ghoshal, S. (2005). Bad management theories are destroying good management practices. Academy of Management Learning \& Education, 4(1), 75-91. http://dx.doi.org/10.5465/AMLE.2005.16132558

Ghoshal, S., \& Moran, P. (1996). Bad for practice: A critique of Transaction Cost Theory. Academy of Management Review, 2l(1), 13-47. http://dx.doi.org/10.5465/AMR.1996.9602161563

Guadagnoli, E., \& Velicer, W. F. (1988). Relation of sample size to the stability of component patterns. Psychological Bulletin, 103(2), 265-275. http://dx.doi.org/10.1037/0033-2909.103.2.265

Guttman, L. (1955). A generalized simplex for factor analysis. Psychometrika, 20, 173-192. http://dx.doi.org/10.1007/BF02289015

Hayton, J. C., Allen, D. G., \& Scarpello, V. (2004). Factor retention decisions in exploratory factor analysis: A tutorial on parallel analysis. Organizational Research Methods, 7(2), 191-205. http://dx.doi.org/10.1007/BF02289015

Heath, C. (1999). On the social psychology of agency relationships: Lay theories of motivation overemphasize extrinsic incentives. Organizational Behavior and Human Decision Processes, 78(1), 25-62. http://dx.doi.org/10.1006/obhd.1999.2826 
Herzberg, F. (1987). One more time: How do you motivate employees? Harvard Business Review, (September/October), 5-16.

Hinkle, D. E., Wiersma, W., \& Jurs, S. G. (2003). Applied statistics for the behavioral sciences. Boston, MA: Houghton Mifflin.

Hinkle, D. E., \& Oliver, J. (1983). How large should the sample be? A question with no simple answer? Or . . . Educational and Psychological Measurement, 43(4), 1051-1060. http://dx.doi.org/10.1177/001316448304300414

Jensen, M. C., \& Meckling, W. H. (1976). Theory of the firm: Managerial behavior, agency costs, and ownership structure. Journal of Financial Economics, 3, 305-360. http://dx.doi.org/10.1016/0304-405X(76)90026-X

Kahan, D. M. (2013). Ideology, motivated reasoning, and cognitive reflection. Judgment and Decision Making, 8(4), 407-424. http://dx.doi.org/10.2139/ssrn.2182588

Kleinginna, P. R., \& Kleinginna, A. M. (1981). A categorized list of motivation definitions with a suggestion for a consensual definition. Motivation and Emotion, 5(3), 263-291. http://dx.doi.org/10.1007/BF00993889

Levinson, H. (1973). Asinine attitudes toward motivation. Harvard Business Review, 51(1), 70-76. http://dx.doi.org/10.1080/00313830701356166

Lewin, K. (2008). Conduct, knowledge, and acceptance of new values. In Resolving Social Conflicts and Field Theory in Social Science (Seventh., pp. 48-55). Washington, D.C. http://dx.doi.org/10.1037/10269-004

Locke, E. A. (1975). Personnel attitudes and motivation. Annual Review of Psychology, 26(1), 457-480. http://dx.doi.org/10.1146/annurev.ps.26.020175.002325

Locke, E. A., \& Latham, G. P. (2006). New directions in goal-setting theory. Current Directions in Psychological Science, 15(5), 265-268. http://dx.doi.org/10.1111/j.1467-8721.2006.00449.x

MacCallum, R. C., Widaman, K. F., Zhang, S., \& Hong, S. (1999). Sample size in factor analysis. Psychological Methods, 4(1), 84-99. http://dx.doi.org/10.1037/1082-989X.4.1.84

Markóczy, L., \& Deeds, D. L. (2009). Theory building at the intersection: Recipe for impact or road to nowhere? Journal of Management Studies, 46(6), 1076-1088. http://dx.doi.org/10.1111/j.1467-6486.2009.00849.x

Mayer, J. D., Faber, M. a., \& Xu, X. (2007). Seventy-five years of motivation measures (1930-2005): A descriptive analysis. Motivation and Emotion, 31(2), 83-103. http://dx.doi.org/10.1007/s11031-007-9060-2

McClelland, D. C. (1967). The Achieving Society. New York, NY: Free Press.

McClelland, D. C., \& Winter, D. G. (1969). Motivating economic achievement. New York, NY: Free Press.

McClelland, D. C. (1987). Human motivation. New York, NY: Cambridge University Press.

McClelland, D. C., \& Boyatzis, R. E. (1982). Leadership motive pattern and long-term success in management. Journal Of Applied Psychology, 67(6), 737-743. http://dx.doi.org/10.1037/0021-9010.67.6.737

McClelland, D. C., \& Burnham, D. H. (2003). Power is the great motivator. Harvard Business Review, (1), 117-126.

McClelland, D. C., Clark, R. A., Roby, T. B., \& Atkinson, J. W. (1958). The effect of the need for achievement on thematic apperception. In J.W. Atkinson (Ed.), Motives in Fantasy, Action, and Society (pp. 64-82). Princeton, NJ: Van Norstrand.

McGrath, R. E. (2005). Conceptual complexity and construct validity. Journal of Personality Assessment, 85(2), 112-124. http://dx.doi.org/10.1207/s15327752jpa8502_02

McGregor, D. (1960). The human side of enterprise: Annotated edition. New York, NY: McGraw-Hill.

McMahan, E. A., \& Estes, D. (2010). Measuring lay conceptions of well-being: The Beliefs about Well-Being Scale. Journal of Happiness Studies, 12(2), 267-287. http://dx.doi.org/10.1007/s10902-010-9194-x

Millward, L. J., \& Hopkins, L. J. (1998). Psychological contracts, organizational and job commitment. Journal of Applied Social Psychology, 28(16), 1530-1556. http://dx.doi.org/10.1111/j.1559-1816.1998.tb01689.x

Murray, H. A. (1938). Explorations in Personality. New York, NY: Oxford University Press

Nisbett, R. E., \& Ross, L. (1980). Human Inference: Strategies and Shortcomings in Social Judgment. Englewood Cliffs, NJ: Prentice Hall. http://dx.doi.org/10.1521/soco.1982.1.1.83 
Nunnally, J. C. (1978). Psychometric theory. New York, NY: McGraw-Hill. http://dx.doi.org/10.1177/014662167900300216

Osterloh, M., Frost, J., \& Frey, B. (2002). The dynamics of motivation in new organizational forms. International Journal of the Economics of Business, 9(1), 61-77. http://dx.doi.org/10.1080/13571510110102976

Pfeffer, J. (2005). Why do bad management theories persist? Academy of Management Learning \& Education, 4(1), 96-100. http://dx.doi.org/10.5465/AMLE.2005.16132570

Pinder, C. C. (2008). Work motivation in organizational behavior. New York, NY: Psychology Press.

Podsakoff, P. M., Bommer, W. H., Podsakoff, N. P., \& MacKenzie, S. B. (2003). Relationships between leader reward and punishment behavior and subordinate attitudes, perceptions, and behaviors: A meta-analytic review of existing and new research. Organizational Behavior and Human Decision Processes, 99, 113-142. http://dx.doi.org/10.1016/j.obhdp.2005.09.002

Reeve, J. (2009). Understanding human motivation and emotion. Hoboken, NJ: Wiley \& Sons.

Reise, S. P., Waller, N. G., \& Comrey, A. L. (2000). Factor analysis and scale revision. Psychological Assessment, 12(3), 287-297. http://dx.doi.org/10.1037//1040-3590.12.3.287

Rokeach, M., \& Kliejunas, P. (1972). Behavior as a function of attitude-toward-object and attitude-toward-situation. Journal Of Personality And Social Psychology, 22(2), 194-201. http://dx.doi.org/10.1037/h0032614

Roth, A. G., \& Assor, A. (2010). Parental conditional regard as a predictor of deficiencies in young children's capacities to respond to sad feelings. Infant and Child Development, 477, 465-477. http://dx.doi.org/10.1002/icd

Royle, M., \& Hall, A. T. (2012). The relationship between McClelland's theory of needs, feeling individually accountable, and informal accountability for others. International Journal Of Management \& Marketing Research, 5(1), 21-42.

Ryan, R. M., \& Deci, E. L. (1996). When paradigms clash: Comments on Cameron and Pierce's claim that rewards do not undermine intrinsic motivation. Review of Educational Research, 66(1), 33-38. http://dx.doi.org/10.3102/00346543066001033

Schein, E. (2004). Organizational culture and leadership. San Francisco, CA: Jossey-Bass. http://dx.doi.org/10.1177/027046769401400247

Schmitt, N. (1996). Uses and abuses of coefficient alpha. Psychological Assessment, 8(4), 350-353. http://dx.doi.org/10.1037/1040-3590.8.4.350

Senge, P. M. (1990). The fifth discipline: The art and practice of the learning organization. New York, NY: Doubleday.

Shah, J., \& Gardner, W. L. (Eds.). (2008). Handbook of motivation science (pp. 3-22). New York, NY: The Guilford Press.

Sheldon, K. M., \& Schachtman, T. R. (2007). Obligations, internalization, and excuse making: Integrating the triangle model and self-determination theory. Journal of Personality, 75(2), 359-381. http://dx.doi.org/10.1111/j.1467-6494.2006.00442.x

Shah, J., \& Gardner, W. L. (Eds.). (2008). Handbook of motivation science (pp. 3-22). New York, NY: The Guilford Press.

Simons, T. (2002). Behavioral Integrity: The perceived alignment between managers' words and deeds as a research focus. Organization Science, 13(1), 18-35. http://dx.doi.org/10.1287/orsc.13.1.18.543

Skinner, B. F. (1974). About behaviorism. New York, NY: Random House.

Van Eerde, W., \& Thierry, H. (1996). Vroom's expectancy models and work-related criteria: A meta-analysis. Journal of Applied Psychology, 81(5), 575-586. http://dx.doi.org/10.1037/0021-9010.81.5.575

van Emmerik, H., Gardner, W. L., Wendt, H., \& Fischer, D. (2010). Associations of culture and personality with McClelland's motives: A cross-cultural study of managers in 24 countries. Group \& Organization Management, 35(3), 329-367. http://dx.doi.org/10.1177/1059601110370782

Van Nuland, H. J. C., Dusseldorp, E., Martens, R. L., \& Boekaerts, M. (2010). Exploring the motivation jungle: Predicting performance on a novel task by investigating constructs from different motivation perspectives in tandem. International Journal of Psychology, 45(4), 250-9. http://dx.doi.org/10.1080/00207591003774493 
Velicer, W. F., \& Fava, J. L. (1998). The affects of variable and subject sampling on factor pattern recovery. Psychological Methods, 3, 231-251. http://dx.doi.org/10.1037/1082-989X.3.2.231

Vogt, P. W. (2005). Dictionary of statistics and methodology. Thousand Oaks, CA: Sage Publications.

Vroom, V. H. (1995). Work and motivation. San Francisco, CA: Jossey-Bass.

Wheeler, A., Richey, R., Tokkman, M., \& Sablynski, C. J. (2006). Retaining employees for service competency: The role of corporate brand identity. Journal Of Brand Management,14(1/2), 96-113. http://dx.doi.org/10.1057/palgrave.bm.2550062

Williams, G. C., McGregor, H., Sharp, D., Levesque, C., Kouides, R. W., Ryan, R. M., \& Deci, E. L. (2006). Testing a self-determination theory intervention for motivating tobacco cessation: Supporting autonomy and competence in a clinical trial. Health Psychology, 25(1), 91-101. http://dx.doi.org/10.1037/0278-6133.25.1.91

Zwick, W. R., \& Verlicer, W. F. (1986). Comparison of five rules for determining the number of components to retain. Psychological Bulletin, 99(3), 432-442. http://dx.doi.org/10.1037/0033-2909.99.3.432

\section{Appendix A}

\section{Motivation Beliefs Inventory}

Note. These items and the Motivation Beliefs Inventory instrument are propriety and copyrighted by David C. Facer, Jr. They cannot be reproduced without written consent. Please contact at davidf-13@sandiego.edu.

(C) Copyright 2014 David C. Facer, Jr.

\begin{tabular}{|c|l|}
\hline \hline 1 & $\begin{array}{l}\text { Employees' motivation is enhanced over the long term when they believe that the organization's interests and } \\
\text { goals are aligned with their personal interests and goals. }\end{array}$ \\
\hline 2 & For most employees, the probability of success usually determines how much effort they will put in. \\
\hline 3 & Employees' motivation is highest when they believe their effort will lead to good results. \\
\hline 4 & Employees are more likely to strive for achievement when faced with hard goals rather than easy goals. \\
\hline 5 & $\begin{array}{l}\text { Employees experience greater vitality and well-being when they engage in tasks that contribute to something } \\
\text { greater than themselves. }\end{array}$ \\
\hline 6 & Consistent availability of incentives and rewards is essential for sustaining employee motivation. \\
\hline 7 & An employee's motivation is maximized when they believe they can accomplish the desired result. \\
\hline 8 & $\begin{array}{l}\text { Accomplishing something that has never been done before is more motivating to employees than receiving the } \\
\text { compensation or reward. }\end{array}$ \\
\hline 9 & At work, punishment is an effective way to eliminate unwanted behavior. \\
\hline 10 & $\begin{array}{l}\text { At work, an employee's motivation is significantly influenced by how mutually supportive their relationships are } \\
\text { with others. }\end{array}$ \\
\hline 11 & Striving to accomplish something that has never been done before is naturally motivating to most employees. \\
\hline 12 & Employee behavior at work can be reliably controlled through the use of rewards and/or punishment. \\
\hline 13 & Highly challenging goals stimulate employees' need for achievement more than less challenging goals. \\
\hline 14 & $\begin{array}{l}\text { At work, people are more likely to engage in a task, activity, or project when they think the probability of success } \\
\text { is high. }\end{array}$ \\
\hline 15 & Rewards and/or punishment are a good way to get an employee to focus on what is important. \\
\hline 16 & Employees' motivation is maximized when asked to achieve challenging goals. \\
\hline 17 & When the probability of achieving a particular outcome is low, so is the motivation to strive for that outcome. \\
\hline 18 & $\begin{array}{l}\text { More than just wanting to be increasingly competent, employees have an inherent desire to grow as human } \\
\text { beings. }\end{array}$ \\
\hline 19 & Employees naturally want to engage in work that allows them to express their personal values and interests. \\
\hline 20 & Employee behavior is easily changed by new reward systems. \\
\hline \hline
\end{tabular}

